University of Nebraska - Lincoln

DigitalCommons@University of Nebraska - Lincoln

Jay F. Storz Publications

Papers in the Biological Sciences

December 2002

\title{
Contrasting Patterns of Divergence in Quantitative Traits and Neutral DNA Markers: Analysis of Clinal Variation
}

Jay F. Storz

University of Nebraska - Lincoln, jstorz2@unl.edu

Follow this and additional works at: https://digitalcommons.unl.edu/bioscistorz

Part of the Genetics and Genomics Commons

Storz, Jay F., "Contrasting Patterns of Divergence in Quantitative Traits and Neutral DNA Markers: Analysis of Clinal Variation" (2002). Jay F. Storz Publications. 16.

https://digitalcommons.unl.edu/bioscistorz/16

This Article is brought to you for free and open access by the Papers in the Biological Sciences at DigitalCommons@University of Nebraska - Lincoln. It has been accepted for inclusion in Jay F. Storz Publications by an authorized administrator of DigitalCommons@University of Nebraska - Lincoln. 
Published in Molecular Ecology 11:12 (December 2002), pp. 2537-2551; doi 10.1046/j.1365-294X.2002.01636.x

Copyright () 2002 Blackwell Science Ltd. Used by permission.

http://www3.interscience.wiley.com/journal/117989598/home

Submitted August 8, 2002; revised and accepted August 21, 2002.

\title{
Contrasting Patterns of Divergence in Quantitative Traits and Neutral DNA Markers: Analysis of Clinal Variation
}

\author{
Jay F. Storz \\ Department of Ecology and Evolutionary Biology, \\ University of Arizona, Biosciences West, Tucson, AZ 85721, USA
}

\begin{abstract}
Clinal variation in quantitative traits is often attributed to the effects of spatially varying selection. However, identical patterns can be produced by the interplay between purely stochastic processes (i.e. drift in combination with spatially restricted gene flow). One means of distinguishing between adaptive and nonadaptive causes of geographical variation is to compare relative levels of betweenpopulation divergence in quantitative traits and neutral DNA markers. Such comparisons can be used to test whether levels of trait divergence attributable to additive genetic effects (as measured by $Q_{\mathrm{ST}}$ ) exceed null expectations based on the level of divergence at neutral marker loci (as measured by $F_{\mathrm{ST}}$ ). The purpose of this study was to use an approach based on " $Q_{\mathrm{ST}} \mathrm{vs} . F_{\mathrm{ST}}$ " contrasts to test for evidence of diversifying selection on body size of an Indian fruit bat, Cynopterus sphinx (Chiroptera: Pteropodidae). Specifically, relative levels of between-population divergence in body size and microsatellite DNA markers were compared to assess whether the observed pattern of clinal size variation could be explained by a neutral model of isolation by distance. $Q_{\mathrm{ST}}$ for body size was calculated using unbiased estimators of within- and between-population variance of principal component scores. The association between body size variation and geographical/environmental distance was tested using pairwise and partial matrix correspondence tests (MCTs). Independent variables (representing causal hypotheses) were constructed as between-locality distance matrices. The effects of neutral genetic divergence were assessed by including a matrix of pairwise $F_{\mathrm{ST}}$ as an independent variable. Partial MCTs revealed highly significant associations between phenotypic divergence $\left(Q_{\mathrm{ST}}\right)$ and both geographical and environmental distance, even when the effects of neutral genetic divergence $\left(F_{\mathrm{ST}}\right)$ were partialled out. Results of the tests confirmed that migration-drift equilibrium is not a sufficient explanation for the latitudinal pattern of clinal size variation in C. sphinx. The geographical patterning of pairwise $Q_{\mathrm{ST}}$ is most likely attributable to spatially varying selection and/or the direct influence of latitudinally ordered environmental effects.
\end{abstract}

Keywords: bats, Bergmann's rule, Cynopterus sphinx, isolation by distance, microsatellite DNA, phenotypic divergence, $Q_{\mathrm{ST}}$

\section{Introduction}

Clinal variation in genetically based traits can provide compelling evidence for spatially varying selection across an environmental gradient (Haldane 1948; Slatkin 1973, 1978; Endler 1977). Clines are of particular interest in highly vagile species because their persistence requires recurrent selection to counterbalance the homogenizing effect of gene flow. However, there are also alternative explanations for the stable maintenance of clinal variation that do not invoke spatially varying selection. Clinal variation in allelic frequencies at genes underlying a particular trait can result from gene flow between partially isolated populations that have diverged in genetic composition via drift, or admixture between two or more genetically differentiated founding populations. As stated by Gould \& Johnston (1972: p. 459), “... [clines] can be just as well explained by a nonselective isolation-by-distance model as by an appeal to selection by correlated environmental factors." The rela- 
tive importance of adaptive and nonadaptive causes of clinal variation is an issue of central importance to our understanding of local adaptation and the determinants of geographical variation (Mayr 1963; Felsenstein 1976; Endler 1977; García-Ramos \& Kirkpatrick 1997)In some cases, an inductive approach can be used to infer the causes of clinal variation in ecologically important traits. Because stochastic processes such as drift and gene flow are not expected to produce systematic patterns of variation in allelic frequencies, parallel clines in geographically isolated populations of the same species strongly implicate an adaptive basis for geographical differentiation. For example, parallel clines in body size of Drosophila subobscura on different continents implicate spatially varying selection as the driving force of phenotypic divergence across latitudinal gradients (Huey et al. 2000). A more general approach to infer the role of selection in maintaining clinal variation is to compare relative levels of between-population divergence in quantitative traits and neutral DNA markers. When testing for the effects of spatially varying selection, the null hypothesis is that the level of trait divergence attributable to additive genetic effects (as measured by $Q_{\mathrm{ST}}$ ) does not exceed the level of divergence at neutral loci (as measured by $F_{\mathrm{ST}}$; Wright 1943, 1951; Rogers \& Harpending 1983; Zeng \& Cockerham 1991; Prout \& Barker 1993; Spitze 1993).

\section{Phenotypic divergence and isolation by distance}

When a species is distributed across an environmental selection gradient, a joint analysis of phenotypic divergence and isolation by distance for neutral DNA markers can elucidate the spatial scale at which adaptation to local conditions can evolve in response to diversifying selection. Consider the case of a species with strong dispersal capabilities (high gene flow) that is distributed across a continuous climatic gradient where environmental similarity is a linear function of spatial proximity. If selection on a particular trait is mediated by spatially varying environmental factors, the disparity in trait optima between populations increases as a function of distance. In accordance with the intraspecific interpretation of Bergmann's rule (Mayr 1963; James 1970), such a pattern might be expected when populations of a homeothermic animal species are sampled across a latitudinal gradient in temperature, humidity, rainfall, or other factors that influence local optima for body size.

If the observed cline in trait values is solely attributable to isolation by distance, $Q_{\mathrm{ST}}$ for the trait and $F_{\mathrm{ST}}$ for neutral markers should exhibit concordant patterns of increase with geographical distance. Conversely, if the cline in trait values reflects adaptation to spatially varying environmental conditions, $Q_{\mathrm{ST}}$ for the trait should exceed $F_{\mathrm{ST}}$ for neutral markers. The role of selection in maintaining clinal variation is most clearly revealed when a species has not attained migration-drift equi- librium under high levels of gene flow (such that neutral loci do not conform to an isolation-by-distance relationship). Under such circumstances, $Q_{\mathrm{ST}}$ is expected to increase as a positive function of distance while $F_{\mathrm{ST}}$ should exhibit no significant correlation with distance at any spatial scale.

The purpose of this study was to use an approach based on " $Q_{\mathrm{ST}}$ vs. $F_{\mathrm{ST}}$ " contrasts to test for evidence of diversifying selection on body size of an Indian fruit bat, Cynopterus sphinx (Chiroptera: Pteropodidae). Specifically, relative levels of between-population divergence in body size and microsatellite DNA markers were compared to assess whether the observed pattern of clinal size variation can be explained by a neutral model of isolation by distance.

\section{Materials and methods}

\section{Study species, study area, and sampling design}

Cynopterus sphinx is a medium-sized fruit bat with an average wingspan of $380 \mathrm{~mm}$ (Bates \& Harrison 1997; Storz \& Kunz 1999). It is one of the most widely distributed and abundant fruit bats in the Indo-Malayan Region, and is not known to undergo seasonal migrations (Corbet \& Hill 1992; Storz \& Kunz 1999). In peninsular India, the geographical pattern of variation in external morphology of C. sphinx conforms to Bergmann's rule, as indicated by a steep, monotonic cline of increasing body size from south to north (Storz et al. 2001a). In the present study, a total of 251 adult C. sphinx (95 males and 156 females) were sampled for a joint analysis of morphometric and genetic variation. Bats were sampled from eight localities along a latitudinal transect that spanned a linear distance of $1080 \mathrm{~km}$ across peninsular India, from $18^{\circ} 32^{\prime} \mathrm{N}, 73^{\circ} 51^{\prime} \mathrm{E}$ (Pune) to $9^{\circ} 56^{\prime} \mathrm{N}, 7^{\circ} 07^{\prime} \mathrm{E}$ (Othakadai; Figure 1). All available evidence indicates that C. sphinx is continuously distributed across the region surveyed in this study (Corbet \& Hill 1992; Bates \& Harrison 1997; Storz \& Kunz 1999). The latitudinal transect was orientated along the eastern flanks of the Western Ghats, a mountain range that parallels the western coast of the subcontinent. The crestline of the Western Ghats averages $900-1,500 \mathrm{~m}$ in elevation and intercepts the southwest monsoon, thereby creating a rain shadow across the semiarid plains to the east. Sampling localities were situated in semiarid tropical thorn-scrub/secondary forest habitat (Mani 1974b; Subramanyam \& Nayar 1974) at elevations ranging from 30 to $900 \mathrm{~m}$. The latitudinal transect spanned a north-to-south gradient of increasing temperature and relative humidity (Mani 1974a; Ramdas 1974; Storz et al. 2001a). The annual range of ambient temperature also varies with latitude in peninsular India, decreasing from the more seasonal Deccan Plateau in the north to the more equable climate of the Tamilnad Plains in the south. 


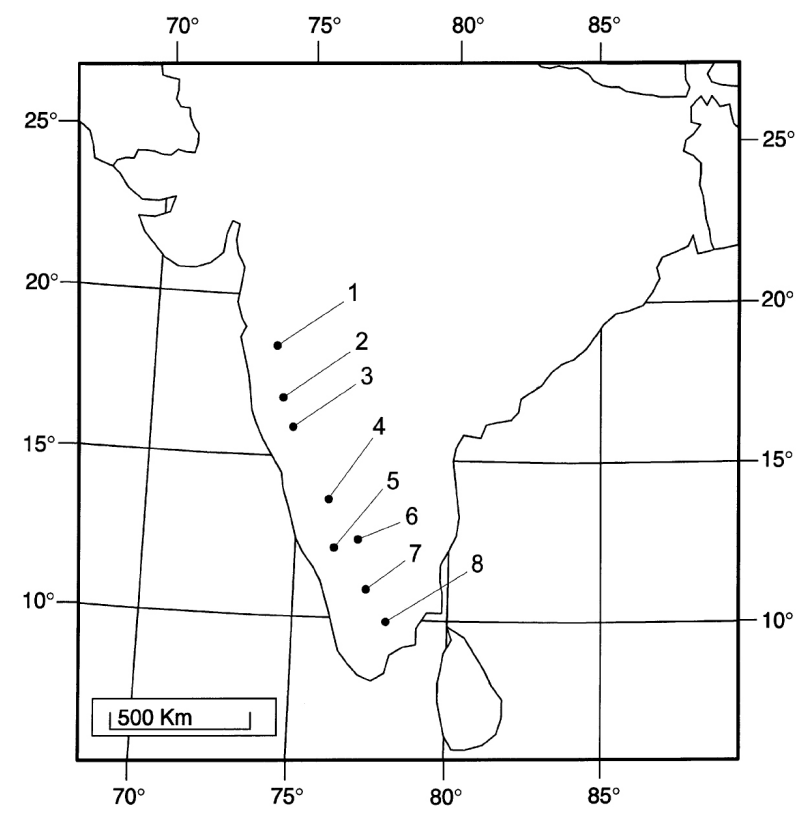

Figure 1. Map of peninsular India showing localities where Cynopterus sphinx was sampled for the joint analysis of morphometric and genetic variation. Names of sampling localities, geographical coordinates, and elevation (recorded to the nearest $10 \mathrm{~m})$ are as follows: 1) Pune, Maharashtra $\left(18^{\circ} 32^{\prime} \mathrm{N}\right.$ $\left.\left.73^{\circ} 51^{\prime} \mathrm{E}, 600 \mathrm{~m}\right) ; 2\right)$ Kolhapur, Maharashtra $\left(16^{\circ} 42^{\prime} \mathrm{N} 74^{\circ} 13^{\prime} \mathrm{E}\right.$,

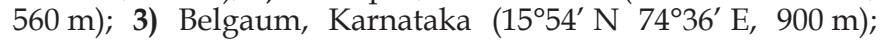

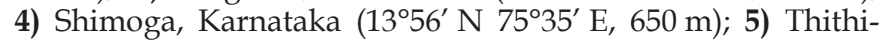
mathi, Karnataka $\left(12^{\circ} 05^{\prime} \mathrm{N} 76^{\circ} 00^{\prime}\right.$ E, $\left.860 \mathrm{~m}\right)$; 6) Mysore, Karnataka (12 $\left.18^{\prime} \mathrm{N} 76^{\circ} 37^{\prime} \mathrm{E}, 780 \mathrm{~m}\right) ; 7$ ) Metupalayam, Tamil Nadu $\left(11^{\circ} 18^{\prime} \mathrm{N} 76^{\circ} 59^{\prime} \mathrm{E}, 450 \mathrm{~m}\right)$; and 8) Othakadai, Tamil Nadu (9॰56’ N 7807’ E, $150 \mathrm{~m})$.

Bats were trapped at foraging and roosting sites (Storz et al. 2000a,b 2001a) and wing-membrane biopsies were taken as a source of DNA for the genetic analysis (see Storz et al. 2001b,c). All bats were sampled during an 8-week period during the dry-season breeding period (4 March to 2 May 1998). Each individual was classified as juvenile or adult based on the degree of fusion of the metacarpal-phalangeal epiphyses (Anthony 1988). Only adults were used in the subsequent analysis of morphometric and genetic variation, and bats were released at the site of capture after processing.

\section{Analysis of morphometric variation}

Morphometric variation of C. sphinx was assessed by examining eight external characters that jointly summarize overall body dimensions and wing area (Storz et al. 2001a): length of tibia, length of forearm, length of metacarpal of digits $2-5$, proximal phalanx of digit 3 , and body mass. Univariate normality and equality of error variances were confirmed for $\log _{10}$-transformed values of each trait.

In bats, a multivariate axis that summarizes body and wing dimensions can provide a functionally relevant measure of overall structural size (Storz et al. 2001a). Accordingly, principal components analysis was performed on the variance-covariance matrix of seven $\log _{10}$-transformed morphometric variables (all characters except body mass) to extract a multivariate index of overall body size. If the first axis of a principle components analysis (PC1) provides an accurate and functionally meaningful representation of overall structural size, PC1 scores and body mass should covary in a positive, linear fashion (Rising \& Somers 1989). This relationship was tested by means of bivariate correlation analysis. Sexual dimorphism and geographical variation in sexual dimorphism were examined by performing a mixed model two-way analysis of variance (ANOVA) on PC1 scores with sex and geographical locality included as fixed-effects and random-effects factors, respectively. Additionally, sex differences in patterns of clinal size variation were examined by testing for differences in slopes from a regression of PC1 scores on latitude (Zar 1999; pp. 360-364).

If the geographical patterning of additive genetic variance underlying a particular trait is exclusively attributable to migration-drift equilibrium (and if there are no departures from allelic or genotypic equilibria within populations), variance components can be defined as $\sigma_{\mathrm{b}}^{2}=2 F_{\mathrm{ST}_{2}} \sigma_{0}^{2}, \sigma_{\mathrm{w}}^{2}=\left(1-F_{\mathrm{ST}}\right) \sigma_{0}^{2}$, and $\sigma_{\mathrm{t}}^{2}=\left(1+F_{\mathrm{ST}}\right) \sigma_{0}^{2}$ where $\sigma_{\mathrm{w}}, \sigma_{\mathrm{b}}^{2}$, and $\sigma_{\mathrm{t}}^{2}$ represent the within-population, between-population, and total genetic variances in the trait, respectively, and $\sigma_{0}^{2}$ represents the total variance in the trait under panmixia (Wright 1943, 1951; Rogers \& Harpending 1983; Lande 1992; Spitze 1993). Thus, a dimensionless measure of differentiation for quantitative traits, analogous to Wright's (1951) $F_{\mathrm{ST}}$, can be defined as

$$
Q_{\mathrm{ST}}=\sigma_{\mathrm{b}}^{2} /\left(\sigma_{\mathrm{b}}^{2}+2 \sigma_{\mathrm{w}}^{2}\right)
$$

(Wright 1951; Spitze 1993). The partitioning of phenotypic variance within and between populations of $C$. sphinx was assessed using a two-way ANOVA on PC1 scores, as above, with sex included as a fixed-effects factor. Variance components were estimated by equating observed mean squares $(M S)$ to their expectations (Spitze 1993; Lynch \& Walsh 1998). $M S_{\text {within }}$ is an unbiased estimate of the within-population variance $\left(\sigma_{w}^{2}\right)$ and $M S_{\text {between }}$ is an unbiased estimate of the between-population variance $\left(\sigma^{2}{ }^{2}+n_{0} \sigma_{b}^{2}\right)$, where $n_{0}$ is the average sample size and $\sigma_{b}^{2 \mathrm{w}}$ is the added variance component attributable to differences between populations (Sokal \& Rohlf 1995; pp. 208-217). For each comparison, the average sample size $n_{0}$ was calculated as

$$
n_{0}=\frac{1}{a-1}\left(\sum^{a} n_{i}-\frac{\sum_{a} n_{i}^{2}}{\sum_{a} n_{i}}\right)
$$

where $a=$ number of populations compared and $n=$ number of individuals in the $i$ th population sample. The 
added component of variance between populations was estimated as

$$
\operatorname{Var}(b)=\left(M S_{\text {between }}-M S_{\text {within }}\right) / n_{0}
$$

Using estimates of the within- and between-population variance components $[\operatorname{Var}(w)$ and $\operatorname{Var}(b)$, respectively], $Q_{\mathrm{ST}}$ for body size of $C$. sphinx was calculated for each pairwise combination of populations using equation 1. Standard errors for estimates of variance components were obtained using the delta method (Kendall \& Stuart 1977; Lynch \& Walsh 1998).

$Q_{\mathrm{ST}}$ can be interpreted as an $F_{\mathrm{ST}}$-analogue for quantitative traits provided that within- and between-population variance in trait values is exclusively attributable to additive genetic effects (Wright 1943; Rogers \& Harpending 1983). Otherwise, $Q_{\mathrm{ST}}$ estimates may be biased if within- and between-population components of environmental variance are not proportional. Since data in the present study are purely phenotypic, estimation of within-population variance requires an assumption about heritability of body size. Following Merilä (1997), $Q_{\mathrm{ST}}$ for body size of $C$. sphinx was calculated by substituting the observed phenotypic variance for $2 \operatorname{Var}(w)$. This is equivalent to assuming that body size (as indexed by PC1) has a narrow-sense heritability $\left(h^{2}\right)$ of 0.5 . Empirical estimates of $h^{2}$ for mammalian body size suggest that this is a reasonable assumption (Falconer \& Mackay 1996). As will be demonstrated, the environmental component of the between-population variance in body size would have to be extremely large (and $h^{2}$ would have to be extremely high) to accept the null hypothesis of neutral phenotypic divergence.

\section{Analysis of microsatellite DNA variation}

Genomic DNA was isolated from tissue samples of $C$. sphinx using QIAamp extraction columns (Qiagen Inc., Valencia, CA). Genetic analysis was based on a total of six polymorphic microsatellite loci: two di-, two tri-, and two tetranucleotide repeats. Primer sequences and polymerase chain reaction protocols were reported previously (Storz 2000; Storz et al. 2001b,c). Allele sizes were quantified using a 377 ABI Prism automated sequencer and analyzed using genescan software (PE Applied Biosystems). Sequencing of alleles confirmed that length polymorphism at each locus was attributable to variation in the copy-number of a single repeat motif. Nei's (1987) average gene diversity $(H)$ was computed for each population, and arcsine-transformed values were used to test for a correlation with latitude. Partitioning of genetic variance within and among populations was assessed using Weir \& Cockerham's (1984) estimators of F-statistics: $f\left(=F_{\mathrm{IS}}\right), F\left(=F_{\mathrm{IT}}\right)$, and $\theta\left(=F_{\mathrm{ST}}\right)$. Ninety five per cent confidence intervals were obtained by bootstrapping over loci. Null hypotheses of Hardy-Weinberg genotypic proportions $\left(F_{\mathrm{IS}}=0\right.$ and $\left.F_{\mathrm{IT}}=0\right)$ were tested us- ing a randomization procedure. Null distributions were generated from 10,000 randomizations of alleles among individuals within populations (for $F_{\mathrm{IS}}$ ) and among individuals sampled across the total array of populations (for $F_{\mathrm{IT}}$ ). Since $F_{\mathrm{ST}}$ is based on the infinite alleles model of mutation (Kimura \& Crow 1964), its suitability for the analysis of microsatellite variation depends on the spatial and/or temporal scale of divergence under consideration. Slatkin $(1991,1993)$ derived expressions for inbreeding coefficients in terms of allelic genealogies and demonstrated that $F_{\mathrm{ST}}$ measures the difference in withinand between-population coalescence times scaled by the average coalescence time. As a measure of genetic divergence, $F_{\mathrm{ST}}$ is therefore independent of mutation rate $(\mu)$, provided that the average coalescence time is less than $1 / \mu$. Simulation results of Slatkin (1993) indicate that high mutation rates characteristic of microsatellite loci could potentially mask a pattern of isolation by distance. For comparative purposes, genetic divergence was also assessed using $R_{\mathrm{ST}}$ (based on the stepwise mutation model; Ohta \& Kimura 1973; Valdes et al. 1993; Slatkin 1995). After standardizing allele lengths (zero mean, unit variance), Goodman's (1997) $\rho$ was used as an estimator of $R_{\mathrm{ST}}$. The programs fstat version 2.9.1 (updated from Goudet 1995) and $R_{\mathrm{ST}}$ calc (Goodman 1997) were used for all calculations.

Since simple-sequence repeats are largely restricted to noncoding regions of the genome, microsatellite variation is generally considered to be selectively neutral (Schlötterer \& Wiehe 1999). The validity of this assumption was evaluated for the markers used in this study by comparing observed $F_{\mathrm{ST}}$ values to a null distribution of values generated by a coalescent-based simulation model. Specifically, the model of Beaumont \& Nichols (1996) was used to generate the expected neutral distribution of $F_{\mathrm{ST}}$ as a function of single-locus heterozygosity. Coalescent simulations were performed using a symmetrical 100-island model of population structure, with sample sizes of 30 diploid individuals (= median of actual sample sizes). Two separate sets of simulations were performed in which mutational dynamics conformed to either the infinite alleles model or the stepwise mutation model. To generate a wide range of heterozygosity values, simulations were based on two different mutation rates $\left(N_{e} \mu=0.1\right.$ and 1.0, where $N_{e} \mu$ is the mutation rate scaled to effective population size).

\section{Testing the neutral model of isolation by distance}

Measures of genetic differentiation (hereafter, " $F_{\mathrm{ST}}$ ") were calculated for all pairwise combinations of populations, as were straight-line geographical distances. To test for isolation by distance, pairwise $F_{\mathrm{ST}}$ values were arcsine-transformed and regressed against ln-transformed measures of separation distance. Since the nonindependence of pairwise comparisons precludes the 
use of parametric tests based on the $t$ - or F-distributions, statistical significance of regression coefficients was assessed by means of a matrix randomization test (Manly 1997). A computer program was used to create a null distribution of regression coefficients by iteratively randomizing the order of elements in the dependent variable matrix. Probability values for the null hypothesis of no association were then expressed as the proportion of 10000 randomizations that yielded $t$ values greater than or equal to the observed value. To test for an increase in residual variance of pairwise $F_{\mathrm{ST}}$ as a positive function of distance, residuals from the linear regression of arcsin $\sqrt{ } F_{\mathrm{ST}}$ on ln-distance were regressed against ln-distance. Again, statistical significance was assessed using matrix randomization.

If clinal size variation of C. sphinx is simply attributable to isolation by distance, the positive association between $Q_{\mathrm{ST}}$ and separation distance should disappear when the effects of neutral genetic divergence (as measured by $F_{\mathrm{ST}}$ for microsatellites) are held constant. By contrast, the null hypothesis of isolation by distance would be rejected if the increase in pairwise $Q_{\mathrm{ST}}$ as a function of geographical/environmental distance remained statistically significant after controlling for pairwise $F_{\mathrm{ST}}$. A significant partial regression of pairwise $Q_{\mathrm{ST}}$ on distance would indicate that migration-drift equilibrium is not a sufficient explanation for the latitudinal pattern of clinal size variation in C. sphinx.

The association between body size variation and geographical/environmental distance was tested using pairwise and partial matrix correspondence tests (MCTs; Thorpe 1996; Manly 1997; Malhotra \& Thorpe 2000). Pairwise MCTs involve comparisons of one dependent and one independent variable matrix, while partial MCTs involve simultaneous tests of multiple independent matrices (also known as "multiple Mantel tests"; Manly 1997). To test causal hypotheses about clinal size variation in C. sphinx, partial MCTs were performed using a stepwise multiple regression procedure for ecogeographic variables that showed a significant degree of association in pairwise tests. For the partial MCTs, a

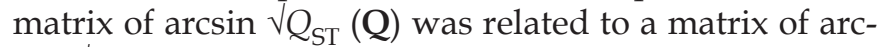
$\sin \sqrt{ } F_{\mathrm{ST}}(\mathbf{F})$ and a matrix of pairwise measures of geographical or environmental distance (D; see below). For the three respective matrices, let $q_{i j} f_{i j}$ and $d_{i j}$ denote distances between localities $i$ and $j$. The following multiple regression model was then evaluated:

$$
q_{i j}=\beta_{0}+\beta_{1} f_{i j}+\beta_{2} d_{i j}+\varepsilon_{i j}
$$

where $\beta_{2}$ measures the association between $q_{i j}$ and $d_{i j}$ while controlling for the effects of $f_{i j^{\prime}}$ and $\varepsilon_{i j}$ represents an independent error term. The statistical significance of the association between the dependent variable matrix $\mathbf{Q}$ and the two independent variable matrices (F and $\mathbf{D})$ was assessed by means of a randomization test (Manly 1997).
In addition to the tests based on linear measures of geographical distance, MCTs were performed using pairwise measures of environmental distance. The purpose was to examine the relationship between size variation and the following climatological variables: mean annual temperature, mean maximum daily temperature, mean minimum daily temperature, mean annual range in temperature, mean relative humidity, mean annual rainfall, mean maximum rainfall during the wettest month, and mean minimum rainfall during the driest month. Long-term meteorological data were obtained for each sampling locality as described in Storz et al. (2001a). To control for multicollinearity, temperature and precipitation variables were reduced to a smaller set of orthogonal vectors by means of principal components analysis on the correlation matrix. Climatic principal components were then used to construct distance matrices for use as independent variables in the partial MCT. Distances for each matrix element were computed as $\sqrt{ }\left(X_{k i}-X_{k j}\right)^{2}$, where $X_{k i}$ and $X_{k j}$ represent principal component scores on the $k$ th axis in the $i$ th and $j$ th populations. In all pairwise and partial MCTs, the matrix element representing the Thithimathi-Mysore comparison was excluded because these two localities were closely situated at the same latitude (Figure 1).

A potential problem with partial MCTs arises when two or more explicative factors (e.g. independent matrices of pairwise $F_{\mathrm{ST}}$ and pairwise distance) are involved in predicting the elements of a response value (e.g. the matrix of pairwise $Q_{\mathrm{ST}}$ ). If permutations of the response matrix do not preserve the spatial order of the geographical localities, the effects of spatial autocorrelation will not necessarily be removed by including a matrix of pairwise $F_{\mathrm{ST}}$ values in the multiple regression model. In the presence of spatial autocorrelation, the same permutation procedure that is valid for testing the independence of two matrices (the traditional Mantel test) is not necessarily valid when testing for partial effects of a second predictive factor. Consequently, the $P$ value derived from the matrix permutations may not be indicative of the true Type 1 error (Oden \& Sokal 1992; Raufaste \& Rousset 2001). One solution to this problem is to apply a form of restricted randomization that accounts for potential sources of autocorrelation in the data (Sokal et al. 1989, 1990; Manly 1997; pp. 188-194). Accordingly, the partial MCTs were performed in such a way that permutations of the response matrix were restricted to spatially defined groups of populations. To account for potential sources of autocorrelation in the data, the following regression model was fitted:

$$
q_{i j}=c_{v(i) v(j)}+\beta_{1} f_{i j}+\beta_{2} d_{i j^{\prime}}
$$

where $c_{v(i) v(j)}$ is a nuisance parameter that takes into account the overall difference between populations in group $i$ and populations in group $j$. This model permits 
an assessment of the association between pairwise $Q_{\mathrm{ST}}$ and geographical or environmental distance after allowing for large-scale differences between spatially defined groups of populations, as well as small-scale differences within groups.

\section{Results}

\section{Morphometric variation}

The first axis of the principal components analysis (PC1) explained $84.6 \%$ of variance in the external morphology of Cynopterus sphinx (eigenvalue $=5.92$ ) and was clearly interpretable as an overall size vector as factor loadings for all characters were uniformly high and positive. Product-moment correlations between the original variables and PC1 factor scores were as follows: $\log _{10}$-length of tibia, $r=0.890 ; \log _{10}$-length of forearm, $r=0.912$; $\log _{10}$-length of metacarpal of digits 2-5, $r=0.943,0.955$, 0.941 , and 0.940 , respectively; and $\log _{10}$-proximal phalanx of digit 3, $r=0.853$. Moreover, in a sample of 232 bats (95 males and 137 nonpregnant females), PC1 was strongly and positively correlated with $\log _{10}$-body mass $(r=0.791, P<0.001)$. No statistically significant departure from normality was detected in the total sample of PC1 scores (one sample Kolmogorov-Smirnov test; $Z=0.759, n=251, P=0.611)$. The two-way ANOVA revealed a highly significant degree of heterogeneity among localities $(P<0.001)$, but no significant effects of sex $(P>0.05)$ or sex $\times$ locality interaction $(P>0.05)$. Moreover, there was no statistically significant sex difference in the slopes of linear regressions of PC1 on latitude $(t=1.269$, sum of residual d.f. $=247, P>0.05)$. Mean PC1 scores exhibited a progressive increase from south to north, indicating a latitudinal cline in overall body size (Figure 2).

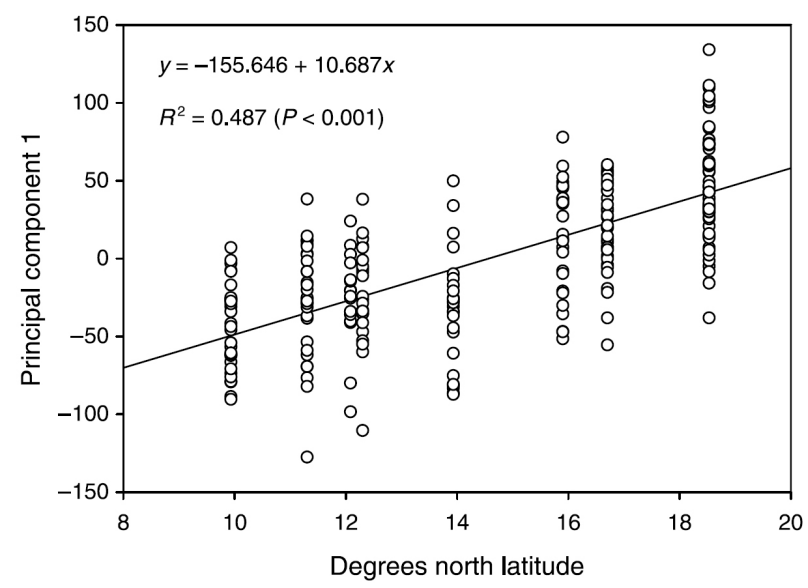

Figure 2. Least-squares linear regression of body size (as indexed by PC1 scores) against latitude for Cynopterus sphinx $(n=251)$ sampled from peninsular India.

\section{Microsatellite variation}

For the total sample of C. sphinx $(n=251)$, mean number of alleles per locus was 11.7 (range $=5-21$ ) and mean observed heterozygosity was 0.73 (range $=0.54-$ 0.79; Table 1). The average within-population inbreeding coefficient was not significantly different from zero $\left(F_{\mathrm{IS}}=0.027,95 \% \mathrm{CI}=-0.004-0.055\right)$. Randomization tests revealed a deficit of heterozygotes relative to HardyWeinberg expectations in two of the 48 locus $\times$ locality combinations (Table 2). However, no $F_{\text {IS }}$ values remained significant at a Bonferroni-adjusted a-level of 0.0010 . There was no significant correlation between gene diversity $(\arcsin \sqrt{ } H)$ and latitude $(r=-0.556, P=0.152)$. The analysis of microsatellite variation revealed a significant degree of genetic subdivision $\left(F_{\mathrm{ST}}=0.030,95 \%\right.$ $\mathrm{CI}=0.013-0.045$; Table 1). Overall estimates of $F_{\mathrm{ST}}$ and $R_{\mathrm{ST}}$ were closely similar in magnitude $(0.030$ vs. 0.033$)$, but pairwise $R_{\mathrm{ST}}$ values were characterized by a much higher variance. Results of the coalescent simulations revealed no evidence for departures from neutral expectations at any locus, regardless of the underlying mutation model $(P>0.05$ for every locus $\times$ model combination). When single-locus $F_{\mathrm{ST}}$ values were plotted as a function of heterozygosity, observed points were well within the 0.025 and 0.975 quantiles of the expected neutral distribution.

Table 1. Patterns of variation at six microsatellite loci used in the genetic analysis of Cynopterus sphinx from peninsular India

\begin{tabular}{lrlllllll}
\hline & & & \multicolumn{5}{c}{$F_{\mathrm{IS}}$} & \multicolumn{2}{c}{$F_{\mathrm{IT}} F_{\mathrm{ST}}$} \\
$\begin{array}{lrrrrrr}\mathrm{ST} \\
\text { Locus }\end{array}$ & \multicolumn{1}{c}{$N_{\mathrm{A}}$} & $H_{\mathrm{O}}$ & $H_{\mathrm{E}}$ & \multicolumn{1}{c}{$(=f)$} & $(=F)$ & $(=\theta)$ & $(=\rho)$ \\
\hline Locus 3 & 13 & 0.78 & 0.83 & 0.043 & 0.063 & 0.021 & 0.016 \\
CSP-1 & 12 & 0.76 & 0.85 & 0.058 & 0.124 & 0.070 & 0.003 \\
CSP-2 & 6 & 0.73 & 0.71 & -0.012 & -0.011 & 0.000 & 0.009 \\
CSP-5 & 13 & 0.79 & 0.79 & -0.030 & 0.002 & 0.031 & 0.062 \\
CSP-7 & 21 & 0.77 & 0.85 & 0.056 & 0.095 & 0.042 & 0.102 \\
CSP-9 & 5 & 0.54 & 0.58 & 0.056 & 0.069 & 0.014 & 0.006 \\
Mean/ & & & & & & & \\
total & 11.7 & 0.73 & 0.77 & 0.027 & 0.057 & 0.030 & 0.033 \\
UL & & & & 0.055 & 0.092 & 0.045 & 0.067 \\
LL & & & & -0.004 & 0.016 & 0.013 & 0.001 \\
\hline
\end{tabular}

$N_{\mathrm{A}^{\prime}}$ number of alleles per locus; $H_{\mathrm{O}^{\prime}}$ observed heterozygosity; and $H_{\mathrm{E}^{\prime}}$ expected heterozygosity. $F_{\mathrm{IS}}$ is defined as the average allelic correlation within individuals relative to local populations and $F_{\mathrm{IT}}$ represents the corresponding allelic correlation relative to the total array of populations. $F_{\mathrm{ST}}$ and $R_{\mathrm{ST}}$ are measures of genetic divergence based on the infinite alleles model and stepwise mutation model, respectively. Ninety-five per cent confidence intervals for $F$ statistics and $R_{\mathrm{ST}}$ were obtained by bootstrapping over loci (UL = upper limit and LL = lower limit). All 251 bats were genotyped at each locus. Locus 3 and CSP-7 are dinucleotide repeats, CSP-1 and CSP-2 are trinucleotide repeats, and CSP-5 and CSP-9 are tetranucleotide repeats. For primer sequences and PCR protocols, see Storz (2000) and Storz et al. (2000b). 
Table 2. Locus-specific summary statistics for eight populations of Cynopterus sphinx sampled in peninsular India

\begin{tabular}{|c|c|c|c|c|c|c|}
\hline \multirow[t]{2}{*}{ Pop. } & \multicolumn{6}{|l|}{ Locus } \\
\hline & Locus 3 & CSP-1 & CSP-2 & CSP-5 & CSP-7 & CSP-9 \\
\hline \multicolumn{7}{|c|}{ Pune $(n=61)$} \\
\hline$N_{\mathrm{A}}$ & 8 & 9 & 5 & 9 & 12 & 4 \\
\hline$H$ & 0.771 & 0.698 & 0.736 & 0.726 & 0.812 & 0.489 \\
\hline$F_{\text {IS }}$ & 0.121 & 0.053 & 0.057 & 0.001 & 0.066 & -0.022 \\
\hline$P$ & 0.052 & 0.257 & 0.267 & 0.548 & 0.166 & 0.645 \\
\hline \multicolumn{7}{|c|}{ Kolhapur $(n=34)$} \\
\hline$N_{\mathrm{A}}$ & 10 & 10 & 5 & 7 & 11 & 5 \\
\hline$H$ & 0.775 & 0.887 & 0.709 & 0.777 & 0.859 & 0.586 \\
\hline$F_{\mathrm{IS}}$ & 0.013 & 0.105 & -0.119 & -0.022 & 0.110 & 0.097 \\
\hline$P$ & 0.521 & 0.082 & 0.918 & 0.683 & 0.087 & 0.271 \\
\hline \multicolumn{7}{|c|}{ Belgaum $(n=29)$} \\
\hline$N_{\mathrm{A}}$ & 9 & 9 & 6 & 6 & 12 & 4 \\
\hline$H$ & 0.805 & 0.810 & 0.703 & 0.757 & 0.864 & 0.683 \\
\hline$F_{\mathrm{IS}}$ & -0.113 & -0.021 & 0.117 & -0.002 & 0.082 & 0.091 \\
\hline$P$ & 0.961 & 0.682 & 0.210 & 0.587 & 0.198 & 0.282 \\
\hline \multicolumn{7}{|c|}{ Shimoga $(n=25)$} \\
\hline$N_{\mathrm{A}}$ & 8 & 8 & 4 & 7 & 10 & 4 \\
\hline$H$ & 0.833 & 0.827 & 0.707 & 0.820 & 0.759 & 0.434 \\
\hline$F_{\text {IS }}$ & -0.008 & 0.178 & -0.131 & -0.073 & -0.212 & -0.013 \\
\hline$P$ & 0.627 & 0.052 & 0.903 & 0.852 & 0.999 & 0.649 \\
\hline \multicolumn{7}{|c|}{ Thithimathi $(n=17)$} \\
\hline$N_{\mathrm{A}}$ & 7 & 7 & 4 & 9 & 7 & 4 \\
\hline$H$ & 0.829 & 0.860 & 0.726 & 0.827 & 0.767 & 0.660 \\
\hline$F_{\mathrm{IS}}$ & 0.078 & 0.316 & -0.053 & -0.067 & 0.002 & 0.109 \\
\hline$P$ & 0.333 & 0.007 & 0.738 & 0.833 & 0.616 & 0.340 \\
\hline \multicolumn{7}{|c|}{ Mysore $(n=23)$} \\
\hline$N_{\mathrm{A}}$ & 9 & 8 & 4 & 5 & 10 & 4 \\
\hline$H$ & 0.837 & 0.780 & 0.703 & 0.688 & 0.834 & 0.624 \\
\hline$F_{\mathrm{IS}}$ & 0.013 & 0.052 & -0.052 & -0.075 & 0.166 & 0.094 \\
\hline$P$ & 0.533 & 0.394 & 0.724 & 0.800 & 0.055 & 0.331 \\
\hline \multicolumn{7}{|c|}{ Metupalayam $(n=30)$} \\
\hline$N_{\mathrm{A}}$ & 9 & 9 & 4 & 10 & 10 & 5 \\
\hline$H$ & 0.867 & 0.846 & 0.699 & 0.855 & 0.791 & 0.589 \\
\hline$F_{\mathrm{IS}}$ & 0.000 & -0.024 & -0.144 & -0.052 & 0.031 & 0.264 \\
\hline$P$ & 0.579 & 0.708 & 0.925 & 0.836 & 0.441 & 0.030 \\
\hline \multicolumn{7}{|c|}{ Othakadai $(n=31)$} \\
\hline$N_{\mathrm{A}}$ & 10 & 10 & 5 & 8 & 11 & 4 \\
\hline$H$ & 0.851 & 0.860 & 0.707 & 0.758 & 0.826 & 0.621 \\
\hline$F_{\text {IS }}$ & 0.128 & -0.051 & 0.087 & -0.021 & 0.102 & -0.091 \\
\hline$P$ & 0.072 & 0.843 & 0.275 & 0.686 & 0.121 & 0.854 \\
\hline
\end{tabular}

$N_{\mathrm{A}^{\prime}}$ number of alleles; $H$, Nei's (1987) gene diversity; $F_{\mathrm{IS}}$, within-population inbreeding coefficient; and $P$, proportion of 10,000 randomizations that yielded $F_{\text {IS }}$ values larger (more positive) than those observed. The number of bats sampled from each population is given parenthetically in the leftmost column. All 251 bats were genotyped at each locus.

\section{Interpreting geographical and environmental distance}

The first axis of the principal components analysis on temperature variables (PC1-T) explained $86.3 \%$ of the variance among localities (eigenvalue $=4.32$ ). Factor loadings were high and positive for each variable (mean annual temperature, $r=0.988$; mean maximum daily temperature, $r=0.882$; mean minimum daily temperature, $r=0.960$; mean relative humidity, $r=0.980)$, except for mean annual range of temperature (an index of seasonality), which was strongly negative $(r=-0.824)$. PC1-T was therefore interpreted as an overall temperature/equability vector. The first axis of the principal components analysis on rainfall variables (PC1-R) explained $71.4 \%$ of the variance among localities (eigenvalue $=2.14$ ). Factor loadings were uniformly high and positive (mean annual rainfall, $r=0.906$; mean maximum rainfall, $r=0.996$; mean minimum rainfall, $r=0.573$ ). PC1-R was therefore clearly interpretable as an overall rainfall vector. Whereas PC1-R scores exhibited no significant association with latitude $(r=0.294$, $P=0.479)$, PC1-T scores exhibited a strong negative correlation $(r=-0.824, P=0.003)$. These results are consistent with a previous analysis of latitudinal variation in climatic factors across peninsular India (Storz et al. 2001a). Principal components analysis of climatic variables thus produced an ordination of sampling localities across a north-to-south gradient of increasing minimum, maximum, and mean temperature, increasing relative humidity, and decreasing seasonality.

Since PC1-T scores were negatively correlated with latitude, and because sampling localities were distributed along a latitudinal transect, dissimilarity in temperature and humidity conditions increased as a positive function of distance. Thus, matrices of geographical and environmental (PC1-T) distance measures were highly correlated (PC1-T and ln-distance, $r=0.607$ ). With the exclusion of the Thithimathi-Mysore comparison, geographical distance among sampling localities can thus be considered a proxy measure of latitudinally ordered environmental variation. Analysis of PC1-T and PC1-R permitted an assessment of the relative importance of two different sources of environmental variation in relation to clinal size variation in C. sphinx.

\section{Relative magnitudes of phenotypic and genetic divergence}

Pairwise estimates of $F_{\mathrm{ST}}$ and $R_{\mathrm{ST}}$ exhibited a monotonic increase as a positive function of distance (Figure 3 ). Matrix randomization tests revealed a statistically significant relationship between arcsin $\sqrt{ } F_{\mathrm{ST}}$ and ln-distance $(r=0.533, P=0.008)$ but not for arcsin $\sqrt{ } R_{\mathrm{ST}}$ and ln-distance $(r=0.226, P=0.255)$. Absolute standardized residuals from a regression of arcsin $\sqrt{ } F_{\mathrm{ST}}$ against ln-distance also exhibited a significant correlation with ln-distance $(r=0.401, P=0.041)$. The correlation between residual $R_{\mathrm{ST}}$ and distance was not statistically significant 

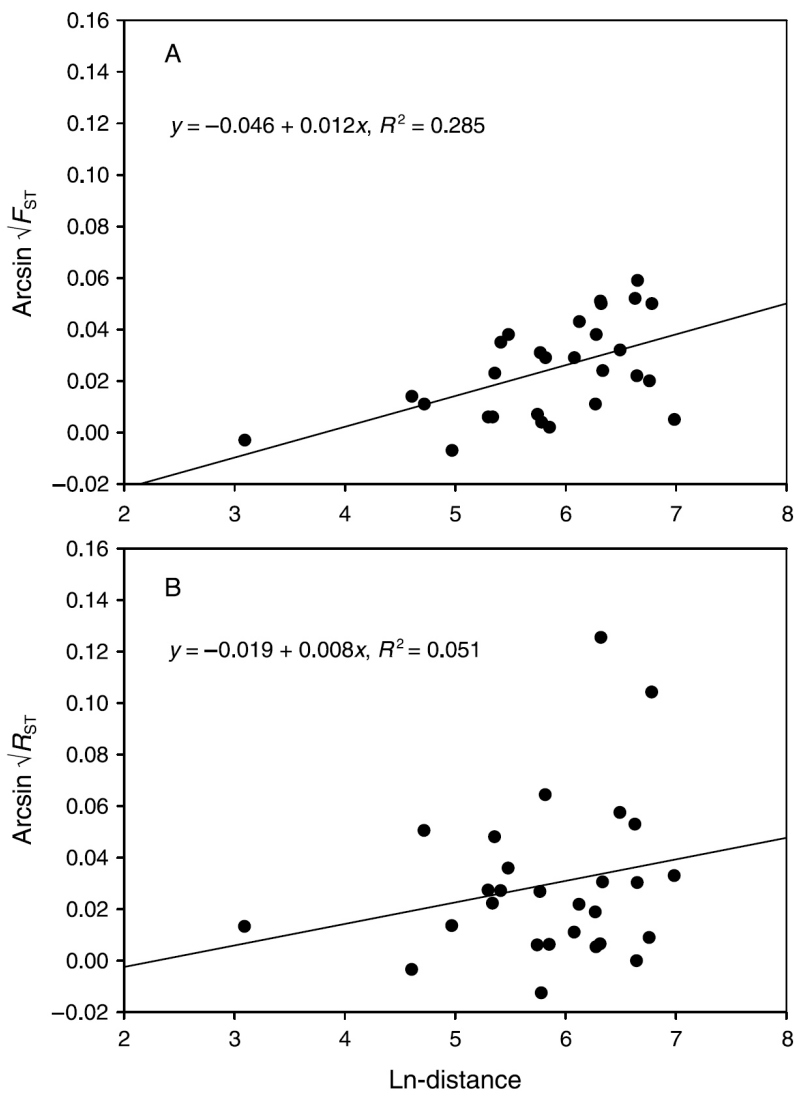

Figure 3. Least-squares linear regression of (A) $\arcsin \sqrt{ } F_{\mathrm{ST}}$ and (B) arcsin $\sqrt{ } R_{\mathrm{ST}}$ against ln-distance for each pairwise combination of populations. As a result of the nonindependence of pairwise comparisons and heterogeneity in error variance, statistical significance of regression coefficients was assessed using a matrix randomization test.

$(r=0.272, P=0.139)$. The higher variance for $R_{\mathrm{ST}}$ relative to $F_{\mathrm{ST}}$ agrees with results of simulation studies (Slatkin 1995; Balloux et al. 2000). For reasons explained in the Discussion, only estimates of $F_{\mathrm{ST}}$ were considered in further analyses.

In the analysis of geographical variation in PC1 scores, there was a significant added variance component in nearly all pairwise comparisons that included one of the three northernmost populations (Table 3). The same pairwise comparisons were also characterized by the largest disparities between $Q_{\mathrm{ST}}$ and $F_{\mathrm{ST}}$ (Table 4). Across the entire transect, the average pairwise estimate of $Q_{\mathrm{ST}}$ was 13.5-fold larger than that of $F_{\mathrm{ST}}(0.323$ vs. 0.024; Table 4). In contrast to the levels of population subdivision observed at microsatellite loci, pairwise $Q_{\mathrm{ST}}$ exhibited a remarkably steep increase as a positive function of distance (Figure 4).

Pairwise MCTs revealed highly significant correlations between $Q_{\mathrm{ST}}$ and the following variables: $F_{\mathrm{ST}}$, geographical distance, and the environmental distance based on the temperature/equability vector (PC1-T; Table 5). The correlation between $Q_{\mathrm{ST}}$ and $F_{\mathrm{ST}}$ is primarily attributable to the large number of cases where both measures were close to zero. Regression coefficients for the matrices of geographical and environmental distance remained highly significant in the partial MCTs. In other words, the increase in $Q_{\mathrm{ST}}$ as a positive function of geographical and environmental distance remained statistically significant even when the effects of neutral divergence $\left(F_{\mathrm{ST}}\right)$ were partialled out. Results of the partial MCTs were almost identical when a matrix of pairwise $R_{\mathrm{ST}}$ was used instead of $F_{\mathrm{ST}}$ as a measure of neutral genetic divergence.

In the restricted randomization tests, matrix permutations were restricted to localities within each of two groups: one consisting of the three northernmost localities and one consisting of all remaining localities to the south. This north-south subdivision of the transect was used because of the especially pronounced disparity between $Q_{\mathrm{ST}}$ and $F_{\mathrm{ST}}$ in pairwise comparisons that included one of the three northernmost populations (Table 4). In these tests the regression coefficients for the matrices of geographical and environmental distance remained significantly greater than zero $(P<0.05)$ even after allowing for overall differences between northern and southern subdivisions of the transect. Thus, results of the restricted randomization tests indicate that the regression coefficients reflect real associations and cannot be explained as artifacts of spatial autocorrelation.

\section{Discussion}

In studies of geographical variation, the scope of inference about the interplay between different evolutionary forces is greatly enhanced when patterns of genetically based trait variation are considered in conjunction with estimates of neutral genetic divergence (Lynch et al. 1999; Merilä \& Crnokrak 2001; McKay \& Latta 2002). For example, a matrix of pairwise estimates of neutral genetic divergence can be used as an independent variable in a partial MCT when the observed pattern of phenotypic divergence is tested against causal hypotheses. This general approach has been used previously to disentangle the effects of phylogenetic history and local adaptation in shaping patterns of morphological variation in island lizards (Thorpe 1996; Thorpe et al. 1996; Gübitz et al. 2000; Malhotra \& Thorpe 2000). An alternative approach employed here is to use partial MCTs based on dimensionless measures of phenotypic and genetic divergence that are directly comparable (e.g. $Q_{\mathrm{ST}}$ for body size and $F_{\mathrm{ST}}$ for microsatellites). The advantage of the approach based on $Q_{\mathrm{ST}}$ vs. $F_{\mathrm{ST}}$ contrasts is that results can be interpreted within the framework of the neutral theory of phenotypic evolution (Lande 1976, 1977, 1992; Chakraborty \& Nei 1982; Rogers \& Harpending 1983; Lynch \& Hill 1986; Lynch 1988, 1994; Whitlock 1999). This approach provides a means of testing long-standing hypotheses about the ecological causes of population differentiation and the role of selection in maintaining clinal variation. 
Table 3. Matrix of $\operatorname{Var}(w)$ (above diagonal) and $\operatorname{Var}(b)$ (below diagonal) for each pairwise combination of populations

\begin{tabular}{lcccccccc}
\hline & PUN & KOL & BEL & SHI & THI & MYS & MET & OTH \\
\hline PUN & - & 1033.635 & 1223.922 & 1246.217 & 1145.269 & 1090.927 & 1210.549 & 1036.261 \\
& & $(47.656)$ & $(107.436)$ & $(486.539)$ & $(419.333)$ & $(351.002)$ & $(443.301)$ & $(590.373)$ \\
KOL & $\mathbf{3 3 3 . 5 8 9}$ & - & 986.216 & 1001.883 & 807.904 & 762.775 & 971.039 & 727.526 \\
& $\mathbf{( 1 4 7 . 6 6 2 )}$ & & $(12.346)$ & $(240.015)$ & $(201.463)$ & $(115.844)$ & $(202.825)$ & $(322.819)$ \\
BEL & $\mathbf{7 2 8 . 6 6 4}$ & -70.922 & - & 1325.366 & 1162.583 & 1069.848 & 1261.750 & 986.955 \\
& $\mathbf{( 1 8 0 . 4 5 8 )}$ & $(171.678)$ & & $(160.334)$ & $(99.231)$ & $(84.679)$ & $(137.546)$ & $(233.565)$ \\
SHI & $\mathbf{3 2 2 7 . 3 3 6}$ & $\mathbf{1 3 3 6 . 3 4 5}$ & $\mathbf{8 4 8 . 4 0 6}$ & - & 1204.235 & 1097.390 & 1304.407 & 1006.834 \\
& $\mathbf{( 1 8 7 . 8 7 4 )}$ & $\mathbf{( 1 7 9 . 9 4 4 )}$ & $\mathbf{( 2 5 0 . 4 7 1 )}$ & & $(3.487)$ & $(3.486)$ & $(0.150)$ & $(8.616)$ \\
THI & $\mathbf{2 6 5 2 . 0 9 4}$ & $\mathbf{1 0 4 6 . 8 3 1}$ & $\mathbf{4 8 6 . 1 2 9}$ & -16.356 & - & 859.255 & 1140.351 & 792.402 \\
& $\mathbf{( 1 8 1 . 0 8 3 )}$ & $\mathbf{( 1 5 5 . 4 8 1 )}$ & $\mathbf{( 2 3 7 . 3 1 1 )}$ & $(256.744)$ & & $(37.587)$ & $(12.183)$ & $(18.120)$ \\
MYS & $\mathbf{2 3 0 1 . 6 7 2}$ & $\mathbf{6 3 4 . 5 0 1}$ & $\mathbf{4 4 0 . 0 0 7}$ & 17.428 & -172.246 & - & 1052.242 & 747.809 \\
& $\mathbf{( 1 6 6 . 3 6 5 )}$ & $\mathbf{( 1 3 9 . 2 6 3 )}$ & $\mathbf{( 2 0 5 . 8 9 2 )}$ & $(219.478)$ & $(187.505)$ & & $(2.996)$ & $(34.940)$ \\
MET & $\mathbf{3 0 2 2 . 9 1 1}$ & $\mathbf{1 1 7 3 . 9 3 3}$ & $\mathbf{7 5 9 . 6 2 5}$ & -0.801 & -60.301 & 15.710 & - & 973.550 \\
& $\mathbf{( 1 7 7 . 5 2 4 )}$ & $\mathbf{( 1 6 7 . 7 7 0 )}$ & $\mathbf{( 2 2 8 . 4 6 7 )}$ & $(244.338)$ & $(230.386)$ & $(200.655)$ & & $(12.843)$ \\
OTH & $\mathbf{4 0 4 7 . 3 9}$ & $\mathbf{1 8 8 2 . 3 3 9}$ & $\mathbf{1 3 0 0 . 4 3 2}$ & 46.400 & 90.599 & $\mathbf{1 8 4 . 8 8 4}$ & 72.081 & - \\
& $\mathbf{( 1 5 1 . 1 5 4 )}$ & $\mathbf{( 1 2 4 . 7 7 0 )}$ & $\mathbf{( 1 7 7 . 2 6 2 )}$ & $(186.964)$ & $(158.480)$ & $\mathbf{( 1 4 1 . 3 2 3 )}$ & $(173.462)$ & \\
\hline
\end{tabular}

Standard errors for estimates of variance components are given in parentheses. $\operatorname{Var}(w)$ and $\operatorname{Var}(b)$ values are method of moments estimates of the within- and between-population variance of PC1 scores, respectively (see text for details). Because mean squares from ANOVA are unbiased estimators of variance components, $\operatorname{Var}(b)$ values may be negative when the parametric variance is close to zero. When there is no added variance component between populations, $M S_{\text {between }}$ is equally likely to be slightly less than or greater than the error mean square $\left(M S_{\text {within }}\right)$. $\operatorname{Var}(b)$ values in bold represent comparisons that revealed a significant added variance component between populations (i.e. when $M S_{\text {between }} / M S_{\text {within }}$ exceeded the one-tailed critical value of the $F$-distribution at $a=0.05$ ). Bold values in italics remained statistically significant at $\alpha=0.00179$ (Bonferroni-adjusted for $0.05 / 28$ comparisons). Three letter abbreviations correspond to sampling localities listed in the legend for Figure 1.

\section{Isolation by distance}

The spatial patterning of pairwise $F_{\mathrm{ST}}$ satisfied two criteria that can be used to determine whether a regional population has attained migration-drift equilibrium: (i) a significant association between pairwise $F_{\mathrm{ST}}$ and distance, and (ii) a scatter-plot of pairwise $F_{\mathrm{ST}}$ vs. distance that reveals a positive and monotonic relationship over the full range of distance values (Hutchison \& Templeton 1999). The first pattern is indicative of isolation-bydistance, and the second pattern reflects the fact that random fluctuations in allelic frequencies increase when the homogenizing effect of gene flow is attenuated between widely separated populations. Thus, the spatial patterning of microsatellite variation indicates that Cynopterus sphinx has attained migration-drift equilibrium under high levels of gene flow across peninsular India.

Genetic evidence suggests that C. sphinx has undergone a population contraction in the Indian subcontinent, possibly as a result of climatically induced range shifts during the late Pleistocene or early to mid-Holocene (Storz \& Beaumont 2002). Thus, we might expect C. sphinx to be characterized by a nonequilibrium mode of population structure that reflects the predominant role of drift relative to gene flow. This mode of population structure would be implicated by a random association between pairwise $F_{\mathrm{ST}}$ and separation distance in conjunction with a wide degree of scatter between plotted points (Hutchison \& Templeton 1999). However, be- cause the observed pattern of microsatellite variation in C. sphinx is consistent with an isolation-by-distance relationship, levels of gene flow across peninsular India must have been high enough to maintain (or re-establish) migration-drift equilibrium following the historical reduction in effective population size.

$Q_{S T}$ vS. $F_{S T}$

As illustrated in Figure 4, patterns of geographical divergence in body size (revealed by $Q_{\mathrm{ST}}$ ) and microsatellite markers (revealed by $F_{\mathrm{ST}}$ ) are highly discordant. Results of the partial MCTs confirmed that migrationdrift equilibrium is not a sufficient explanation for the latitudinal pattern of clinal size variation in C. sphinx. Between-population divergence in body size increased with environmental distance across a north-to-south gradient of increasing temperature, increasing relative humidity, and decreasing seasonality. The geographical patterning of pairwise $Q_{\mathrm{ST}}$ is most likely attributable to spatially varying selection and/or the direct influence of latitudinally ordered environmental effects. However, before invoking selection to explain the observed pattern, it is first necessary to confirm (i) that $F_{\mathrm{ST}}$ for microsatellites provides an unbiased benchmark for the null expectation of neutral divergence and (ii) that $Q_{\mathrm{ST}}$ accurately reflects the partitioning of additive genetic variance in body size. Each of these issues will be discussed in turn. 
Table 4. Matrices of $(\mathrm{A})$ straight-line separation distances $(\mathrm{km}),(\mathrm{B}) Q_{\mathrm{ST}}(\mathrm{C}) F_{\mathrm{ST}}(=\theta)$, and $(\mathrm{D}) R_{\mathrm{ST}}(=\rho)$ for each pairwise combination of populations

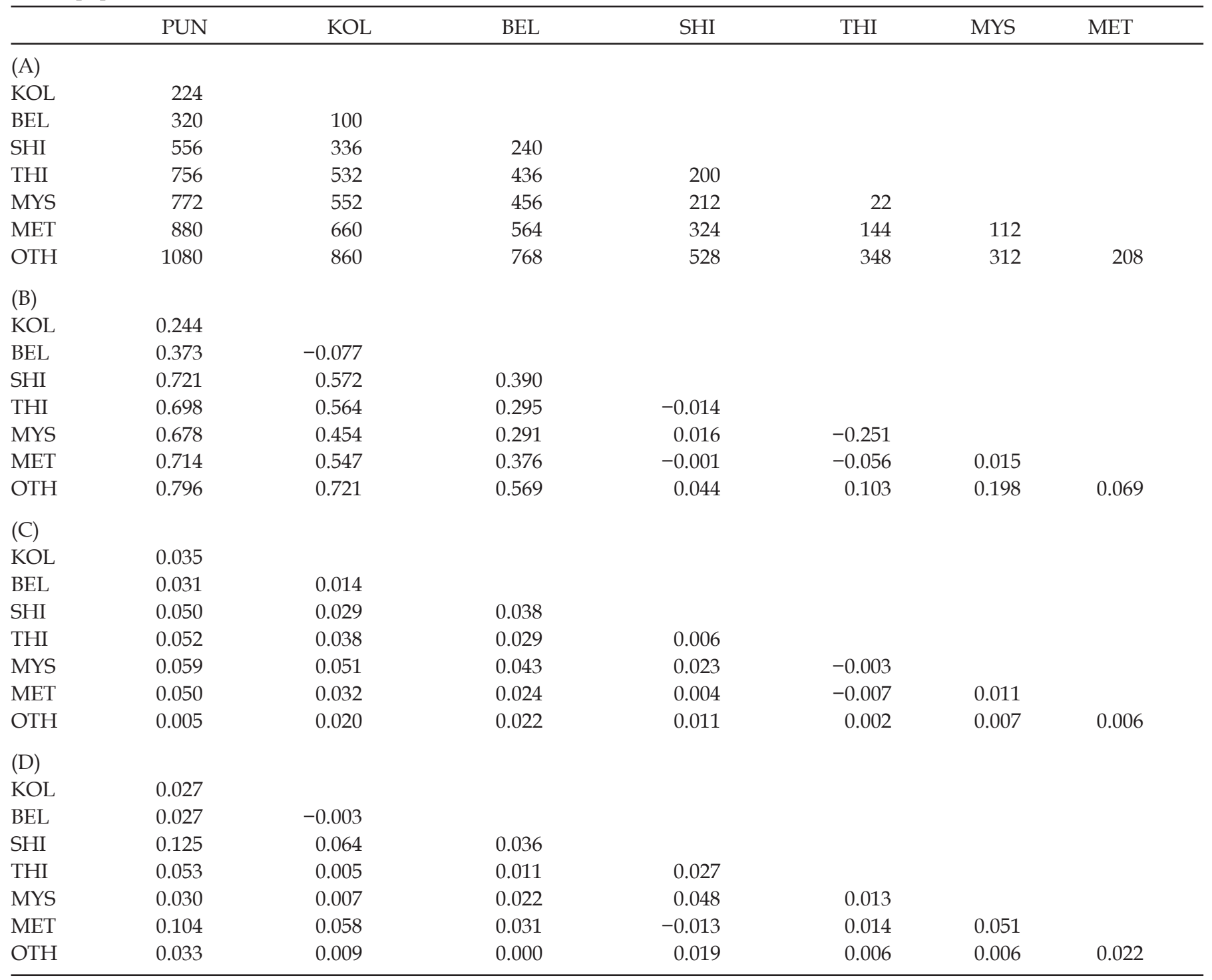

Using the method of moments (Sokal \& Rohlf 1995; Weir 1996), unbiased estimates of variance components were obtained from an ANOVA on PC1 scores $\left(Q_{\mathrm{ST}}\right)$, allelic frequencies $\left(F_{\mathrm{ST}}\right)$, or standardized allelic lengths (in repeat units; $\left.R_{\mathrm{ST}}\right)$. When there is no added variance component between populations, $M S_{\text {between }}$ is equally likely to be slightly less than or greater than the error mean square ( $M S_{\text {within }}$ ). Thus, unbiased estimates of $Q_{\mathrm{ST}}, F_{\mathrm{ST}}$, or $R_{\mathrm{ST}}$ may be negative when the parametric value of the between-population variance is close to zero.

\section{Microsatellites and $F_{S T}$}

High mutation rates characteristic of microsatellite loci may produce a systematic downward bias in $F_{\mathrm{ST}}$ estimates (Charlesworth 1998; Nagylaki 1998; Flint et al. 1999; Hedrick 1999; Balloux et al. 2000). Under equilibrium conditions in an island model of population structure, and assuming that mutational dynamics conform to the infinite alleles model, Wright (1969; p. 291) demonstrated that $F_{\mathrm{ST}}=\left(1+4 N_{e} m+4 N_{e} \mu\right)^{-1}$, where $N_{e}=$ effective size of local populations, $m=$ migration rate, and $\mu=$ mutation rate. When the mutation rate is negligibly small relative to the migration rate, $F_{\mathrm{ST}}$ is a simple function of the number of migrants $\left(N_{e} m\right.$; Crow \& Aoki 1984; Cockerham \& Weir 1993; Neigel 1997). However, depending on the dispersal ability of the species under consideration and the spatial scale at which divergence is being assessed, the mutation rate for microsatellite loci may not be negligibly small relative to migration (Balloux et al. 2000). This problem is further exacerbated if mutational dynamics generate allelic size homoplasy, as expected under the stepwise mutation model (Slatkin 1995; Rousset 1996). 
Table 5. Results of pairwise (A) and partial (B) matrix correspondence tests of causal hypotheses regarding the pattern of clinal size variation in Cynopterus sphinx

\begin{tabular}{|c|c|c|c|c|}
\hline & $\begin{array}{l}\text { Independent variab } \\
\arcsin \sqrt{ } F_{\mathrm{ST}}\end{array}$ & ln-distance & PC1-T distance & PC1-R distance \\
\hline \multicolumn{5}{|c|}{ (A) Pairwise MCTs } \\
\hline \multicolumn{5}{|c|}{ (B) Partial MCTs } \\
\hline $\operatorname{Arcsin} \sqrt{ } Q_{S T}$ & $0.303(P=0.0020)$ & $0.694(P=0.0001)$ & - & - \\
\hline
\end{tabular}

Partial matrix correspondence tests (MCTs) were performed in a stepwise regression procedure for variables that showed a significant degree of association in pairwise tests. A matrix of arcsin $\sqrt{ } F_{\mathrm{ST}}$ was included as an independent variable in each of the partial regression analyses to control for the effects of neutral genetic divergence. Tests were performed on independent variable matrices of pairwise ln-distance and two separate pairwise measures of environmental distance (indexed by PC1-T and PC1-R vectors). PC1-T and PC1-R are multivariate axes that summarize latitudinal variation in temperature and precipitation, respectively. Standardized regression coefficients and associated $P$ values that remained statistically significant after Bonferroni-correction are in bold. $P$ values for one-sided tests are expressed as the proportion of 10000 randomizations that yielded values greater than or equal to observed $t$ values. Since the pairwise MCT revealed no significant matrix correlation between arcsin $\sqrt{ } Q_{\mathrm{ST}}$ and PC1-R distance, the latter variable was not included in the partial MCT with the PC1-T distance matrix.

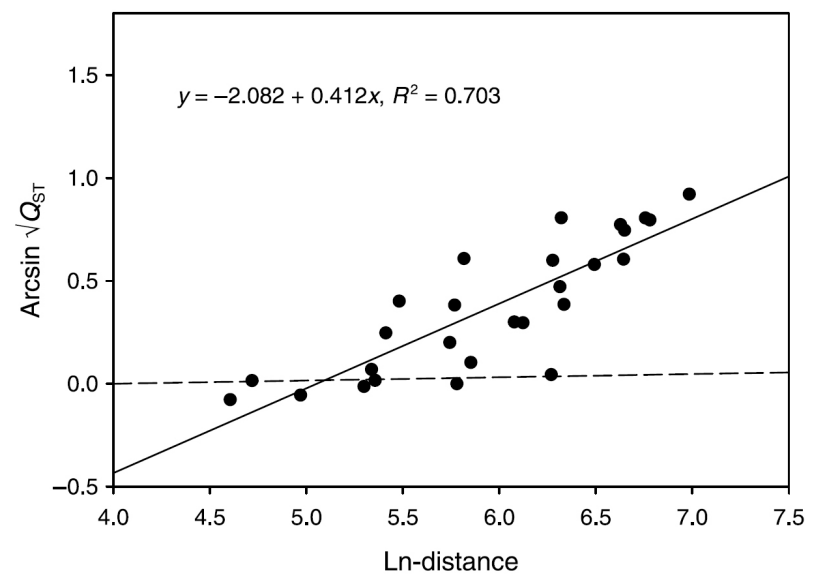

Figure 4. Least-squares linear regression of $\arcsin \sqrt{ } Q_{\mathrm{ST}}$ against ln-distance for each pairwise combination of populations. The dashed line denotes the linear regression line for arcsin $\sqrt{ } F_{\mathrm{ST}}$ vs. distance (note difference in scale of the $y$-axis compared to Figure 3). Statistical significance of the regression coefficient was assessed using a matrix randomization test.

However, the mode of microsatellite mutation should not affect the interpretation of $F_{\mathrm{ST}}$ in this study. Having verified that $C$. sphinx is at migration-drift equilibrium across the region surveyed (see above), the estimate of $F_{\mathrm{ST}}$ for the two most widely separated populations $(=0.005)$ translates into $N_{e}(m+\mu)=49.75$ using Wright's island model approximation. The northern population in this comparison (Pune) has an estimated effective size of $108.2\left(N_{e} / N=0.42\right.$, average $N=257.5$ adults; Storz et al. 2001c). Thus, even for mutation rates as high as $1 \times 10^{-3}-1 \times 10^{-4}$ per haploid gamete per generation (Ellegren 2000), the gametic migration rate would still have to be several orders of magnitude larger to account for the $F_{\mathrm{ST}}$-based estimate of $N_{\mathrm{e}}(m+\mu)$. Across the spatial scale considered in this study, rates of migration are so high relative to possible rates of mutation that Weir \& Cockerham's (1984) unbiased estimator of $F_{\mathrm{ST}}(=\theta)$ can be expected to provide a more accurate measure of genetic divergence than statistics based on the stepwise mutation model (Slatkin 1995; Gaggiotti et al. 1999). It remains true that high levels of within-population variation can place an upper limit on the maximal value of $F_{\mathrm{ST}}$ (Hedrick 1999). However, the magnitude of the expected reduction in $F_{\mathrm{ST}}$ for highly variable loci (Flint et al. 1999) is not sufficient to explain the profound discrepancies between $Q_{\mathrm{ST}}$ and $F_{\mathrm{ST}}$ observed in this study.

\section{Quantitative traits and $Q_{S T}$}

Whitlock (1999) demonstrated that $Q_{\mathrm{ST}}$ for a neutral quantitative trait with an additive genetic basis is equal to $F_{\mathrm{ST}}$ for a neutral locus in the limit of low mutation rates. This result is quite general for all modes of population structure (see also Lynch 1994). This result lends general support to the use of $Q_{\mathrm{ST}}$ Vs. $F_{\mathrm{ST}}$ contrasts as a means of testing the neutral model of phenotypic divergence (Rogers \& Harpending 1983; Lewontin 1984; Felsenstein 1986; Rogers 1986; Lande 1992; Prout \& Barker 1993; Spitze 1993). An important caveat is that statistical properties of variance ratios such as $Q_{\mathrm{ST}}$ and $F_{\mathrm{ST}}$ are not well understood, and estimation error is likely to be quite large.

It should be noted that the $Q_{\mathrm{ST}}$ vs. $F_{\mathrm{ST}}$ neutrality test is only valid when $Q_{\mathrm{ST}}$ is calculated from trait values. Unless the trait in question is selectively neutral, $Q_{\mathrm{ST}}$ is not equivalent to $F_{\mathrm{ST}}$ for allelic variation at quantitative trait loci (QTLs) underlying the trait (Latta 1998). Selection on quantitative traits has a much greater effect on the covariance of allelic frequencies (the between-population component of linkage disequilibrium; Ohta 1982) than on the variance in allelic frequencies among populations. When spatially varying selection is strong (i.e. 


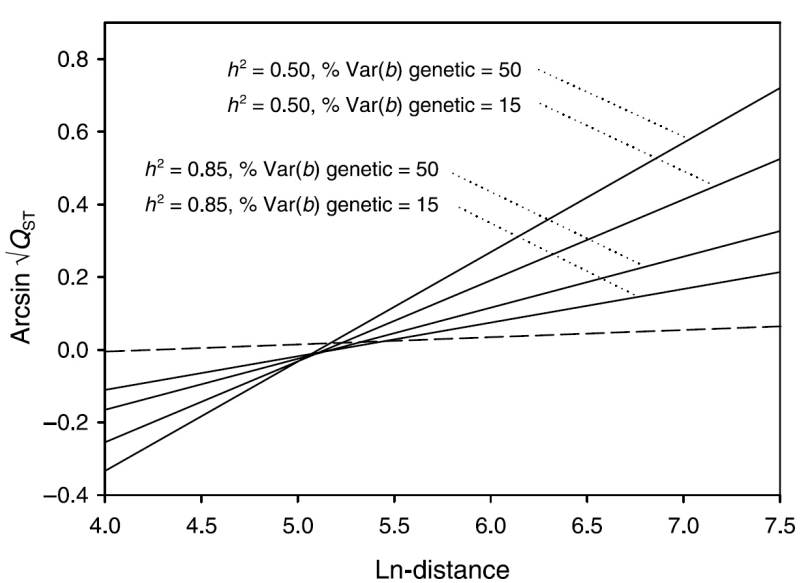

Figure 5. Least-squares linear regression lines for arcsin $\sqrt{ }_{\mathrm{ST}}$ against distance. For each linear regression, $Q_{\mathrm{ST}}$ was recalculated using a range of values for $\operatorname{Var}(w)$ ) (assuming $h^{2}$ in the range $0.50-0.85$ ) and $\operatorname{Var}(b)$ (assuming that $50-85 \%$ of the between-population variance was attributable to a nonheritable environmental component). The dashed line denotes the linear regression line for arcsin $\sqrt{F_{S T}}$ vs. distance (note difference in scale of the $y$-axis compared to Figure 3 )

disparity in trait optima between populations is large) and the rate of gene flow is high, trait divergence may occur as a result of the covariance of allelic effects, even in the absence of appreciable shifts in allelic frequencies at the underlying QTLs. Allelic frequencies of QTLs will depart from the neutral expectation of migration-drift equilibrium only if differences between the variance in trait optima and the between-population variance due to drift $\left(2 F_{\mathrm{ST}} \sigma_{0}^{2}\right)$ exceeds the maximum covariance of allelic frequencies (Latta 1998).

When $Q_{\mathrm{ST}}$ for a particular trait is significantly greater than $F_{\mathrm{ST}}$ for neutral markers (a commonly observed pattern; Lynch et al. 1999; Merilä \& Crnokrak 2001; McKay \& Latta 2002), it is important to confirm that $Q_{\mathrm{ST}}$ estimates are not inflated by nonadditive genetic effects (dominance and/or epistasis) or environmental effects. Theoretical results suggest that dominance and epistasis are unlikely explanations for the observed disparity between $Q_{\mathrm{ST}}$ and $F_{\mathrm{ST}}$. The contribution of dominance variance to $Q_{\mathrm{ST}}$ approaches zero when averaged over a uniform distribution of allelic frequencies (Whitlock 1999). However, the effect of interactions among loci with different allelic frequencies and dominance relationships remains poorly understood. Lynch et al. (1999) suggested that epistatic variance may inflate estimates of $Q_{\mathrm{ST}}$. However, as demonstrated by Whitlock (1999), additive-by-additive epistasis results in an increase in the between-population component of variance on an absolute scale, but $Q_{\mathrm{ST}}$ is actually reduced relative to expectations of the neutral additive model.

Inferences about the adaptive basis of clinal variation are strengthened when the environmental component of phenotypic variation can be identified and sta- tistically removed (Coyne \& Beecham 1987; Mousseau \& Roff 1989, 1995; Long \& Singh 1995; Huey et al. 2000). This can be accomplished by comparing different populations using "common-garden" or reciprocal transplant experiments (Mousseau 1999). Unfortunately, this approach is not practical for many vertebrate species. Provided that certain restrictive conditions apply, a possible alternative is to use genetic marker-inferred relatedness to estimate variance components in free-ranging populations (Mousseau et al. 1998; Ritland 1999; 2000). In this study, within-population phenotypic variance $(\times 0.5)$ was used as a proxy for additive genetic variance. A similar approach has been used to assess the role of selection and/or environmental effects in determining geographical patterns of morphometric variation in human populations in the Solomon Islands (Rogers \& Harpending 1983) and populations of the greenfinch (Carduelis chloris) in continental Europe (Merilä 1997). Although the polygenic basis of mammalian body size has been well characterized (Falconer \& Mackay 1996), ecological considerations suggest that size may be particularly responsive to environmental induction (phenotypic plasticity). For example, variation in postnatal growth rate and onset of sexual maturity can both exert a strong influence on adult body size.

To examine the effects of different assumptions about the genetic basis of body size variation in C. sphinx, $Q_{\mathrm{ST}}$ was recalculated over a range of values for $\operatorname{Var}(w)$ (assuming $h^{2}$ in the range 0.50-0.85) and $\operatorname{Var}(b)$ (assuming that $50-85 \%$ of the between-population variance was attributable to a nonheritable environmental component). Results of this exercise indicate that over the full range of biologically plausible values for $\operatorname{Var}(w)$ and $\operatorname{Var}(b)$, the linear regression slope for arcsin $\sqrt{ } Q_{\mathrm{ST}} \mathrm{vs}$. ln-distance remained significantly steeper than that for arcsin $\sqrt{F_{\text {ST }}}$ vs. In-distance (Figure 5). When it was assumed that $h^{2}=0.85$ and that $85 \%$ of the between-population variance in body size was attributable to environmental effects [ $\% \operatorname{Var}(b)$ genetic $=15]$, partial MCTs between the recalculated $Q_{\mathrm{ST}}$ matrix and each of the geographical and PC1-T distance matrices remained statistically significant. In conclusion, the environmental component of the between-population variance in body size would have to be extraordinarily large to accept the null hypothesis of neutral phenotypic divergence.

Although the analysis of purely phenotypic data can provide much insight into the evolutionary processes that shape patterns of geographical variation (e.g. Smith et al. 1997; Schneider et al. 1999), controlled breeding experiments are ultimately needed to assess the relative importance of genetically and environmentally based variation in trait values. Even in studies that use breeding experiments to measure the narrow-sense heritability of a particular trait, the between-population component of variance is typically estimated from phenotypic trait values alone (i.e. the additive genetic variance is not 
measured directly). To obtain more refined insights into the evolutionary mechanisms underlying trait divergence, it will be important for future studies to measure directly the additive genetic components of the withinand between-population variance in trait values.

\section{Spatially varying selection, gene flow and clinal variation}

If the observed pattern of clinal size variation in C. sphinx has an adaptive genetic basis, what are the underlying causes of spatially varying selection? In pteropodid bats, basal metabolic rate is highly size-dependent and medium-sized frugivores such as C. sphinx are typically characterized by precise regulation of body temperature (McNab 1989; McNab \& Bonaccorso 1995). Because the energetics of temperature regulation have important consequences for fecundity, gestation period and rates of postnatal growth in bats (McNab 1982), the ecologically optimal body size of nonmigratory species may be expected to vary geographically as an adaptive response to broad-scale climatic gradients (for review, see Storz et al. 2001a). Although the underlying causes remain to be elucidated, it seems clear that spatially varying selection has played an important role in shaping latitudinal size variation in C. sphinx.

\section{Acknowledgements}

I thank C. López-Fanjul, J. Mercer, R. Miller, B. Payseur, C. Riginos, R. Wayne, and four anonymous reviewers for helpful comments on the manuscript. I am also grateful to H. R. Bhat, J. Balasingh, P. T. Nathan, A. A. Prakash, and D. P. Swami Doss for assistance with field work, and G. Marimuthu, N. Gopukumar Nair, V. Elangovan, J. Koilraj, and E. Rajan for valuable assistance and logistical support in Othakadai. I gratefully acknowledge support from an NIH Postdoctoral Fellowship (F32 HL68487-01) and a Fellowship in Computational Molecular Biology from the Alfred P. Sloan Foundation and U. S. Department of Energy.

\section{References}

Anthony ELP (1988) Age determination in bats. In: Ecological and Behavioral Methods for the Study of Bats (ed. Kunz TH), pp. 47-58. Smithsonian Institution Press, Washington DC.

Balloux F, Brünner H, Lugon-Moulin N, Hausser J, Goudet J (2000) Microsatellites can be misleading: an empirical and simulation study. Evolution, 54, 1414-1422.

Bates PJJ, Harrison DL (1997) Bats of the Indian Subcontinent. Harrison Zoological Museum, Sevenoaks, Kent, UK.

Beaumont MA, Nichols RA (1996) Evaluating loci for use in the genetic analysis of population structure. Proceedings of the Royal Society of London Series B, 263, 1619-1626.

Chakraborty R, Nei M (1982) Genetic differentiation of quantitative characters between populations or species. I. Mu- tation and random genetic drift. Genetical Research, 39, 303-314.

Charlesworth B (1998) Measures of divergence between populations and the effect of forces that reduce variability. Molecular Biology and Evolution, 15, 538-543.

Cockerham CC, Weir BS (1993) Estimation of gene flow from F-statistics. Evolution, 47, 855-863.

Corbet GB, Hill JE (1992). The Mammals of the Indomalayan Region: a Systematic Review. British Museum Publications, Oxford University Press, Oxford.

Coyne JA, Beecham E (1987) Heritability of two morphological characters within and among natural populations of Drosophila melanogaster. Genetics, 117, 727-737.

Crow JF, Aoki K (1984) Group selection for a polygenic behavioral trait: estimating the degree of population subdivision. Proceedings of the National Academy of Sciences of the USA, 81, 6073-6077.

Ellegren H (2000) Microsatellite mutations in the germline: implications for evolutionary inference. Trends in Genetics, 16, 551-558.

Endler JA (1977) Geographic Variation, Speciation, and Clines. Princeton University Press, Princeton.

Falconer DS, Mackay TFC (1996) Introduction to Quantitative Genetics. Longman Science and Technology, Harlow, UK.

Felsenstein J (1976) The theoretical population genetics of variable selection and migration. Annual Review of Genetics, 10, 253-280.

Felsenstein J (1986) Population differences in quantitative characters and gene frequencies: a comment on papers by Lewontin and Rogers. American Naturalist, 127, 731-732.

Flint J, Bond J, Rees DC et al. (1999) Minisatellite mutational processes reduce $\mathrm{F}_{\mathrm{st}}$ estimates. Human Genetics, 105, 567-576.

Gaggiotti OE, Lange O, Rassmann K, Gliddon C (1999) A comparison of two indirect methods for estimating average levels of gene flow using microsatellite data. Molecular Ecology, 8, 1513-1520.

García-Ramos G, Kirkpatrick M (1997) Genetic models of adaptation and gene flow in peripheral populations. Evolution, 51, 21-28.

Goodman SJ (1997) $R_{\mathrm{ST}}$ Calc: a collection of computer programs for calculating estimates of genetic differentiation from microsatellite data and determining their significance. Molecular Ecology, 6, 881-885.

Gould SJ, Johnston RF (1972) Geographic variation. Annual Review of Ecology and Systematics, 3, 457-498.

Goudet J (1995) fstat (Version 1.2): a computer program to calculate F-statistics. Journal of Heredity, 86, 485-486.

Gübitz T, Thorpe RS, Malhotra A (2000) Phylogeography and natural selection in the Tenerife gecko Tarentola delalandii: testing historical and adaptive hypotheses. Molecular Ecology, 9, 1213-1221.

Haldane JBS (1948) The theory of a cline. Journal of Genetics, 48, 277-284.

Hedrick PW (1999) Highly variable loci and their interpretation in evolution and conservation. Evolution, 53, 313-318.

Huey RB, Gilchrist GW, Carlson ML, Berrigan D, Serra L (2000) Rapid evolution of a geographic cline in size in an 
introduced fly. Science, 287, 308-309.

Hutchison DW, Templeton AR (1999) Correlation of pairwise genetic and geographic distance measures: inferring the relative influences of gene flow and drift on the distribution of genetic variability. Evolution, 53, 1898-1914.

James FC (1970) Geographic size variation in birds and its relationship to climate. Ecology, 51, 365-390.

Kendall M, Stuart A (1977) The Advanced Theory of Statistics, Vol. 1. Distribution Theory. 4th edn. Macmillan, New York.

Kimura M, Crow JF (1964) The number of alleles that can be maintained in a finite population. Genetics, 49, 725-738.

Lande R (1976) Natural selection and random genetic drift in phenotypic evolution. Evolution, 30, 314-334.

Lande R (1977) Statistical test for natural selection on quantitative characters. Evolution, 31, 442-444.

Lande R (1992) Neutral theory of quantitative genetic variance in an island model with local extinction and colonization. Evolution, 46, 381-389.

Latta RG (1998) Differentiation of allelic frequencies at quantitative trait loci affecting locally adaptive traits. American Naturalist, 151, 283-292.

Lewontin RC (1984) Detecting population differences in quantitative characters as opposed to gene frequencies. American Naturalist, 123, 115-124.

Long AD, Singh RS (1995) Molecules versus morphology: the detection of selection acting on morphological characters along a cline in Drosophila melanogaster. Heredity, 74, 569-581.

Lynch M (1988) The divergence of neutral quantitative characters among partially isolated populations. Evolution, 42, 455-466.

Lynch M (1994) Neutral models of phenotypic evolution. In: Ecological Genetics (ed. Real LA), pp. 86-108. Princeton University Press, Princeton.

Lynch M, Hill WG (1986) Phenotypic evolution by neutral mutation. Evolution, 40, 915-935

Lynch M, Walsh B (1998) Genetics and Analysis of Quantitative Traits. Sinauer Associates, Sunderland, MA.

Lynch M, Pfrender M, Spitze K et al. (1999) The quantitative and molecular genetic architecture of a subdivided species. Evolution, 53, 100-110.

Malhotra A, Thorpe RS (2000) The dynamics of natural selection and vicariance in the Dominican anole: patterns of within-island molecular and morphological divergence. Evolution, 54, 245-258.

Mani MS (1974a) Limiting factors. In: Ecology and Biogeography in India (ed. Mani MS), pp. 135-158. Dr W. Junk Publishers, the Hague.

Mani MS (1974b) The flora. In: Ecology and Biogeography in India (ed. Mani MS) , pp. 159-177. Dr W. Junk Publishers, the Hague.

Manly FJB (1997) Randomization, Bootstrap and Monte Carlo Methods in Biology. Chapman \& Hall, New York.

Mayr E (1963) Animal Species and Evolution. Belknap Press, Harvard University Press, Cambridge, MA.

McKay JK, Latta RG (2002) Adaptive population divergence: markers, QTL and traits. Trends in Ecology and Evolution, 17, 285-291.
McNab BK (1982) Evolutionary alternatives in the physiological ecology of bats. In: Ecology of Bats (ed. Kunz TH) , pp. 151-200. Plenum Press, New York.

McNab BK (1989) Temperature regulation and rate of metabolism in three Bornean bats. Journal of Mammalogy, 70, 153-161.

McNab BK, Bonaccorso FJ (1995) The energetics of pteropodid bats. In: Ecology, Evolution and Behavior of Bats (eds Racey PA, Swift SM) , pp. 111-122. Oxford University Press, Oxford.

Merilä J (1997) Quantitative trait and allozyme divergence in the greenfinch (Carduelis chloris, Aves: Fringillidae). Biological Journal of the Linnean Society, 61, 243-266.

Merilä J, Crnokrak P (2001) Comparison of genetic differentiation at marker loci and quantitative traits. Journal of Evolutionary Biology, 14, 892-903.

Mousseau TA (1999) Intra- and interpopulation genetic variation. In: Adaptive Genetic Variation in the Wild (eds Mousseau TA, Sinervo B, Endler JA) , pp. 219-250. Oxford University Press, Oxford.

Mousseau TA, Roff DA (1989) Adaptation to seasonality in a cricket: patterns of phenotypic and genotypic variance in body size and diapause expression along a cline in season length. Evolution, 43, 1483-1496.

Mousseau TA, Roff DA (1995) Genetic and environmental contributions to geographic variation in the ovipositor length of a cricket. Ecology, 76, 1473-1482.

Mousseau TA, Ritland K, Heath DD (1998) A novel method for estimating heritability using molecular markers. Heredity, $80,218-224$.

Nagylaki T (1998) Fixation indices in subdivided populations. Genetics, 148, 1325-1332.

Nei M (1987) Molecular Evolutionary Genetics. Columbia University Press, New York.

Neigel JE (1997) A comparison of alternative strategies for estimating gene flow from genetic markers. Annual Review of Ecology and Systematics, 28, 105-128.

Oden NL, Sokal RR (1992) An investigation of three-matrix permutation tests. Journal of Classification, 9, 275-290.

Ohta T (1982) Linkage disequilibrium due to random genetic drift in finite subdivided populations. Proceedings of the $\mathrm{Na}$ tional Academy of Sciences of the USA, 79, 1940-1944.

Ohta T, Kimura M (1973) A model of mutation appropriate to estimate the number of electrophoretically detectable alleles in a finite population. Genetical Research, 22, 201-204.

Prout T, Barker JSF (1993) F statistics in Drosophila buzzatii: selection, population size and inbreeding. Genetics, 134, 369-375.

Ramdas LA (1974) Weather and climatic patterns. In: Ecology and Biogeography in India (ed. Mani MS), pp. 99-134. Dr W. Junk Publishers, the Hague.

Raufaste N, Rousset F (2001) Are partial Mantel tests adequate? Evolution, 55, 1703-1705.

Rising JD, Somers KM (1989) The measurement of overall body size in birds. Auk, 106, 666-674.

Ritland K (1999) Detecting inheritance with inferred relatedness in nature. In: Adaptive Genetic Variation in the Wild (eds Mousseau TA, Sinervo B, Endler JA) , pp. 187-199. Oxford University Press, Oxford. 
Ritland K (2000) Marker-inferred relatedness as a tool for detecting heritability in nature. Molecular Ecology, 9, 1195-1204.

Rogers AR (1986) Population differences in quantitative characters as opposed to gene frequencies. American Naturalist, 127, 729-730

Rogers AR, Harpending HC (1983) Population structure and quantitative characters. Genetics, 105, 985-1002.

Rousset F (1996) Equilibrium values of measures of population subdivision for stepwise mutation processes. Genetics, 142, 1357-1362.

Schlötterer C, Wiehe T (1999) Microsatellites, a neutral marker to infer selective sweeps. In: Microsatellites: Evolution and Applications (eds Goldstein DB, Schlötterer C) , pp. 238248. Oxford University Press, Oxford.

Schneider CJ, Smith TB, Larison B, Moritz C (1999) A test of alternative models of diversification in tropical rainforests: Ecological gradients vs. rainforest refugia. Proceedings of the National Academy of Sciences of the USA, 96, 13869-13873.

Slatkin M (1973) Gene flow and selection in a cline. Genetics, $75,733-756$.

Slatkin M (1978) Spatial patterns in the distribution of polygenic characters. Journal of Theoretical Biology, 70, 213-228.

Slatkin M (1991) Inbreeding coefficients and coalescence times. Genetical Research, 58, 167-175.

Slatkin M (1993) Isolation by distance in equilibrium and nonequilibrium populations. Evolution, 47, 264-279.

Slatkin M (1995) A measure of population subdivision based on microsatellite allele frequencies. Genetics, 139, 457-462.

Smith TB, Wayne RK, Girman D, Bruford MW (1997) A role for ecotones in generating rainforest biodiversity. Science, 276, 1855-1857.

Sokal RR, Rohlf FJ (1995) Biometry. W. H. Freeman, New York.

Sokal RR, Oden NL, Legendre P et al. (1989) Genetic differences among language families in Europe. American Journal of Physical Anthropology, 76, 337-361.

Sokal RR, Oden NL, Legendre P et al. (1990) Genetics and language in European populations. American Naturalist, 135, 157-175.

Spitze K (1993) Population structure in Daphnia obtusa: quantitative genetic and allozymic variation. Genetics, 135, 367-374.

Storz JF (2000) Variation at tri- and tetranucleotide repeat microsatellite loci in the fruit bat genus Cynopterus (Chiroptera: Pteropodidae). Molecular Ecology, 9, 2198-2200.

Storz JF, Kunz TH (1999) Cynopterus sphinx. Mammalian Species, $613,1-8$

Storz JF, Beaumont MA (2002) Testing for genetic evidence of population contraction and expansion: an empirical analysis of microsatellite DNA variation using a hierarchical Bayesian model. Evolution, 56, 154-166.

Storz JF, Balasingh J, Nathan PT, Emmanuel K, Kunz TH (2000a) Dispersion and site-fidelity in a tent-roosting population of the short-nosed fruit bat (Cynopterus sphinx) in southern India. Journal of Tropical Ecology, 16, 117-131.

Storz JF, Bhat HR, Kunz TH (2000b) Social structure of a polygynous tent-making bat, Cynopterus sphinx (Megachiroptera). Journal of Zoology (London), 251, 151-165.
Storz JF, Balasingh J, Bhat HR et al. (2001a) Clinal variation in body size and sexual dimorphism in an Indian fruit bat, Cynopterus sphinx (Chiroptera: Pteropodidae). Biological Journal of the Linnean Society, 72, 17-31.

Storz JF, Bhat HR, Kunz TH (2001b) Genetic consequences of polygyny and social structure in an Indian fruit bat, Cynopterus sphinx. I. Inbreeding, outbreeding, and population subdivision. Evolution, 55, 1215-1223.

Storz JF, Bhat HR, Kunz TH (2001c) Genetic consequences of polygyny and social structure in an Indian fruit bat, Cynopterus sphinx. II. Variance in male mating success and effective population size. Evolution, 55, 1224-1232.

Subramanyam K, Nayar MP (1974) Vegetation and phytogeography of the Western Ghats. In: Ecology and Biogeography in India (ed. Mani MS), pp. 178-196. Dr W. Junk Publishers, the Hague.

Thorpe RS (1996) The use of DNA divergence to help determine the correlates of evolution of morphological characters. Evolution, 50, 524-531.

Thorpe RS, Black H, Malhotra A (1996) Matrix correspondence tests on the DNA phylogeny of the Tenerife lacertid elucidate both historical causes and morphological adaptation. Systematic Biology, 45, 335-343.

Valdes AM, Slatkin M, Freimer NB (1993) Allele frequencies at microsatellite loci: the stepwise mutation model revisited. Genetics, 133, 737-749.

Weir BS (1996) Genetic Data Analysis II. Sinauer Associates, Sunderland, MA.

Weir BS, Cockerham CC (1984) Estimating F-statistics for the analysis of population structure. Evolution, 38, 1358-1370.

Whitlock MC (1999) Neutral additive genetic variance in a metapopulation. Genetical Research, 74, 215-221.

Wright S (1943) Analysis of local variability of flower color in Linanthus parryae. Genetics, 28, 139-156.

Wright S (1951) The genetical structure of populations. Annals of Eugenics, 15, 323-354.

Wright S (1969). Evolution and the Genetics of Populations, Vol. 2. The Theory of Gene Frequencies. University of Chicago Press, Chicago.

Zar J (1999). Biostatistical Analysis. Prentice Hall, Upper Saddle River, NJ.

Zeng ZB, Cockerham CC (1991) Variance of natural genetic variances within and between populations for a quantitative character. Genetics, 129, 535-553.

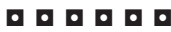

The author's current research concerns molecular population genetics, with an emphasis on understanding the process of adaptive evolutionary change in natural populations. 